VOLUME I4 SUPPL. I PP 85-9I NOVEMBER 2009

\title{
The economic impact of SARS in Beijing, China
}

\author{
Philippe Beutels ${ }^{1,6}$, Na Jia ${ }^{2}$, Qing-Yi Zhou ${ }^{3}$, Richard Smith ${ }^{4}$, Wu-Chun $\mathrm{Cao}^{2}$ and Sake J. de Vlas ${ }^{5}$ \\ 1 Centre for Health Economics Research and Modeling Infectious Diseases, Vaccine and Infectious Disease Institute, Faculty of Medicine, \\ University of Antwerp, Belgium \\ 2 Beijing Institute of Microbiology and Epidemiology State Key Laboratory of Pathogen and Biosecurity, Beijing, P. R. China \\ 3 Public Health Department, Capital Medical University, Beijing, P. R. China \\ 4 Health Policy Unit, London School of Hygiene \& Tropical Medicine, London, UK \\ 5 Department of Public Health, Erasmus MC, University Medical Center Rotterdam, Rotterdam, The Netherlands \\ 6 School of Public Health, University of Sydney, Australia
}

Summary

овJECTIVE To document the impact of the severe acute respiratory syndrome (SARS) outbreak in Beijing on indicators of social and economic activity.

METHODS Associations between time series of daily and monthly SARS cases and deaths and volume of public train, airplane and cargo transport, tourism, household consumption patterns and gross domestic product growth in Beijing were investigated using the cross-correlation function.

RESULTS Significant correlation coefficients were found for all indicators except wholesale accounts and expenditures on necessities, with the most significant correlations occurring with a delay of 1 day to 1 month.

CONCLUSIONS Especially leisure activities, local and international transport and tourism were affected by SARS particularly in May 2003. Much of this consumption was merely postponed; but irrecoverable losses to the tourist sector alone were estimated at about US\$ 1.4 bn, or 300 times the cost of treatment for SARS cases in Beijing.

keywords severe acute respiratory syndrome, economic impact, leisure industry, postponed consumption, losses, People's Republic of China

\section{Introduction}

Severe acute respiratory syndrome (SARS) emerged in late 2002 in the Guandong province of the People's Republic of China. The causative pathogen was identified at the end of February 2003, and the incidence of cases peaked in the second quarter of 2003 in China, as well as various other countries (Donnelly et al. 2004). The eventual global burden of disease in terms of health outcomes was small compared to that of other lethal infectious diseases, but the macroeconomic impact was estimated to be substantial. Most notably the impact on tourism, food and travel was estimated at US\$ 8.5 bn in mainland China, US\$ 4.3 bn in Canada, US\$ 1.4 bn in Malaysia, US\$ 1.3 bn in Hong Kong, US\$ 0.2 bn in Singapore and US\$ 0.1 bn in Australia and Vietnam (Keogh-Brown \& Smith 2008). Additional losses were related to exports and trade, translating into decreases in gross domestic product (GDP) growth. These estimates are crude and not based on the same type of data for each country (for example, the above estimate for Singapore excludes revenue lost to airline carriers). Furthermore, concurrent world events, such as the start of the Second Gulf War, may have influenced these estimates. Nevertheless, the macroeconomic impact of SARS remains of particular interest because it provides an indication of the impact an infectious disease outbreak of international concern may have in the future both in terms of behavioural change and associated economic impact (Beutels et al. 2008, M. R. Keogh-Brown, personal communication). In this short paper we focus on the impact of SARS on various indicators of economic activity in Beijing, the city with the highest attack rate of SARS, using government statistics hitherto undisclosed internationally.

\section{Methods}

We used the SARS incidence and mortality data for the whole of China as reported to WHO, at the time of the crisis, in conjunction with cases reported specifically in Beijing to the authorities (WHO 2008; Ministry of Public Health 2003). These data should mirror the information Chinese people had during the outbreak. Important contextual dates during the outbreak were mainly in the third and fourth week of April, when screening procedures for SARS were 
introduced at airports (April 19th), when the epidemic was officially announced by the government to the people in Beijing (April 20th), when daily reports started on national TV and in newspapers (April 21st), when fever ascertainment was introduced at the Beijing airport (April 22nd) and on trains and buses (April 23rd), when schools and universities in Beijing were closed (April 24th), and when places for entertainment in Beijing were closed (April 26th). On May 22nd the schools in Beijing re-opened.

We verify whether the evolution in the epidemiological data reflects the rise and fall in concern instilled by this outbreak and made evident through the evolution of economic activity in Beijing in particular. Indicators for economic activity were gathered from government statistics on transport, leisure, tourism, general consumption and economic growth (personal communications from Beijing Municipal Statistical Bureau, Beijing Municipal Bureau of Communication, Beijing Municipal Bureau of Tourism, Beijing Commerce Committee, 2005).

The data were analysed as time series, i.e. as a sequence of values of a variable at successive points in time. Where different time series were compared (e.g. SARS cases and number of bus passengers), the time scale and intervals in both series were identical (e.g. daily SARS cases were compared with daily number of bus passengers, and monthly SARS cases with monthly number of bus passengers).

Evolutionary trends were our main focus of analysis, rather than absolute numbers. These trends would be of greater relevance to other countries or other emerging infectious diseases. We limited the scope for impact analysis to a 2-year period (2002-2003), as this was the time window for which these data were available.

A cross-correlation function is a statistical tool assessing direct or delayed correlations between two time series. Correlations between two series can thus be calculated for different time shifts (or 'lags' hereinafter). A significant correlation at lag 0 means that there is a significant association between the evolution of two time series without a delay of one series $v s$. another one. That is, the association between both time series is immediate, without any lag, e.g. if one series shows an increase at day 100, the other series will show a similar increase at day 100 , when the correlation is positive, and a decrease at day 100, when the correlation is negative.

A shifted correlation at lag -1 or -2 means that there is an association between two time series, but with one of the series being shifted by one or two periods, respectively.

That is, for two associated series, if the first series shows a change at day 100, then the second series will show a similar change at day 99 or day 101, for lag +1 and lag -1 , respectively. The extent of the similarity in the evolution of both series is expressed by the correlation coefficient (with one being indicative of identical evolutions), and the significance level of the association is set at twice the standard error. In this paper, we typically report the highest correlation coefficient for which the correlation between two series was found statistically significant, as well as the range of lags over which such a significant correlation was found. This range, by definition, includes the lag at which the greatest significant correlation was found. For instance a significant lag range $(-2,+3)$ means that the evolution of the two series is correlated with shifts of -2 periods, -1 period, 0 periods, +1 period, +2 periods and +3 periods.

We used standard statistical software (SPSS 13.0 ${ }^{\mathrm{TM}}$, SPSS Inc, Chicago, IL, USA) to calculate the cross-correlations between the time series presented here, mainly to identify the lags at which these correlations are greatest, i.e. distinguishing direct (lag 0) from shifted dependencies $(|\operatorname{lag}|>0)$. This technique has also been widely applied in the field of economics, from stock market (Hamori 2003) to presidential popularity analyses (Norpoth 1984). The usual statistical caveats apply in that correlations may reveal associations, but do not prove causality.

\section{Results}

Data available on a daily time scale include number of train passengers arriving to and leaving from Beijing (1st March-30th June) and number of bus passengers in Beijing (21st April-30th June). Figure 1 shows that there was a substantial impact on people's travel habits, with a steep decrease in travel on buses, compared to a year earlier, during the first week of May.

Also the excess of inbound over outbound train passengers was reversed from mid April till end May, suggesting a tendency to leave the urbanized and more densely populated area of Beijing. Note that the number of these train passengers was from January to March 2003 roughly at the same level as in 2002 throughout the year (not shown). These observations by visual inspection are confirmed by high correlation coefficients between the series of daily cases and passengers $(+0.947$ for departing and +0.906 for arriving train passengers, +0.913 for bus passengers, each at lag -1 , and each statistically significant over wide lag ranges $[(-8,+5),(-9,+3)$ and $(-8,+5)$, respectively]. The lag ranges indicate that significant correlations can be found, expressing presumed anticipated (positive lags), immediate (lag 0) and delayed (negative lags) responsiveness to the rise and fall of SARS cases (and public prevention measures) over time. That is, these time series show significant similarities in evolution over a shifted time window of about 14 days.

Daily transport data of train cargo do not show such significant associations, other than that there was a weak 


\section{P. Beutels et al. Economic impact SARS}

Figure I Evolution of daily bus and train usage in Beijing during the severe acute respiratory syndrome (SARS) outbreak in 2003.

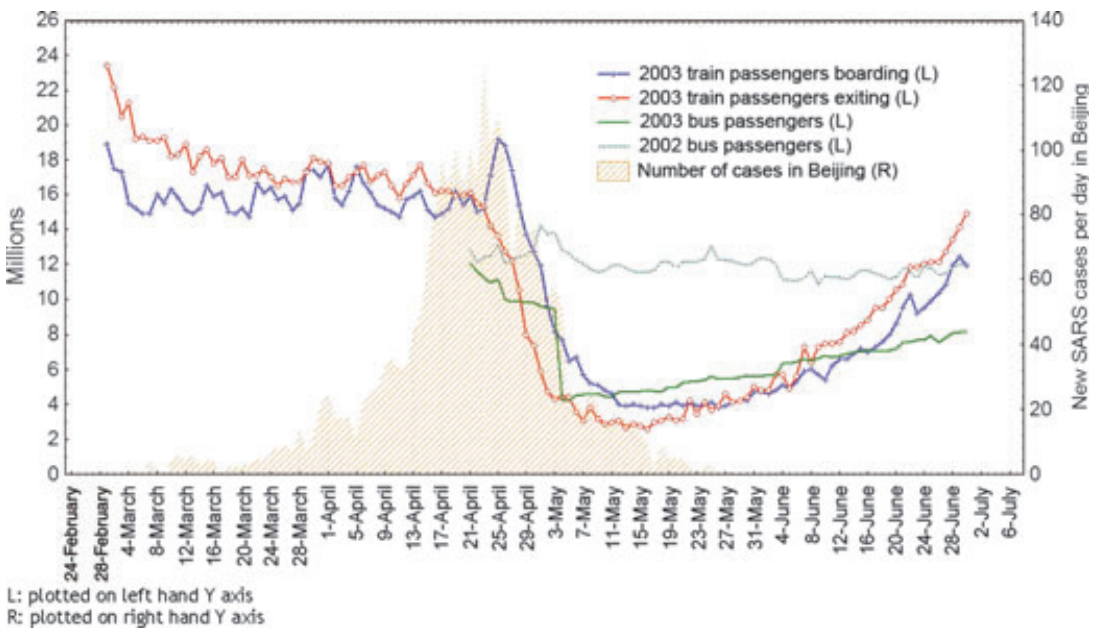

Indeed, in May 2003, 169 new Chinese SARS deaths (49\% of all Chinese SARS deaths) were reported to WHO, lagging about a month the peak in incidence of reported SARS cases, as indicated by the light shaded area in Figure 2. Note, however, that the distribution of reported cases is more peaked than that of reported deaths. Domestic air transport to and from Beijing showed a substantial increase in May 2003 , up by $34 \%$ compared to a year earlier. However, this is contrasted by April, June and July, when domestic air travel decreased compared to a year earlier. In none of the months of 2003, there was a substantial difference between numbers of arriving and departing passengers for domestic air travel. Over the year 2003, there were $0.75 \%$ fewer passengers arriving to, and $0.36 \%$ more passengers departmonth when the reported death toll was highest, as indicated by the dark shaded area plotted on the right hand $Y$-axis.

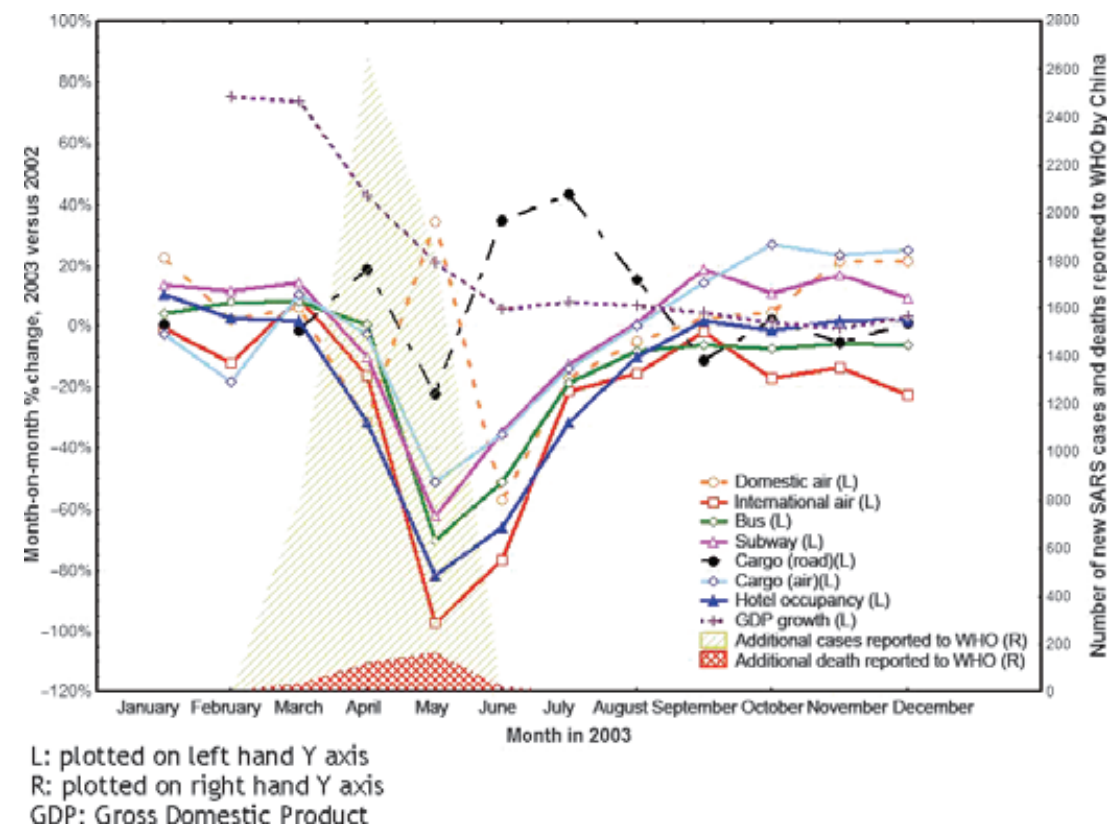

Figure 2 Evolution of monthly indicators of economic activity in Beijing during the severe acute respiratory syndrome (SARS) outbreak in 2003. 
ing from, Beijing on a domestic flight, than in 2002. For international flights these percentages are much higher, $25.0 \%$ and $24.7 \%$, respectively. Furthermore the net influx of international passengers was positive in 2002, with 19000 more passengers arriving than departing, but turned negative in 2003, showing an overall excess of 64000 departing passengers. It is thus hardly surprising that cargo by air decreased substantially (notwithstanding cargo by road was hardly affected). Figure 2 also indicates that as the SARS crisis unfolded, GDP growth, which had been accelerating $v s$. the previous year, slowed down considerably to end at a similar growth rate as the year before. All in all, GDP growth in Beijing was $10.5 \%$ in 2003, vs. $10.2 \%$ in 2002.

Table 1 lists cross-correlations and lags (in months) at which significant correlations were found between a range of monthly economic indicators and monthly reported SARS cases and deaths. In addition to confirming the above observations, Table 1 indicates that most indicators show significant immediate as well as 1 and 2 months delayed negative impacts, with virtually always the most important correlate 1 month delayed (lag -1), and the largest yearon-year drop observed in May.

Table I Lags (in months) at which significant cross-correlations occur (at confidence level of $2 \times$ standard error*), correlation coefficient for most significant lag and year-on-year changes for a range of indicators of socio economic activity

\begin{tabular}{|c|c|c|c|c|c|}
\hline & $\begin{array}{l}\text { SARS cases } \\
\text { Lags with significant } \\
\text { correlation, and } \\
\text { greatest correlation } \\
\text { at boldfaced lag }\end{array}$ & $\begin{array}{l}\text { SARS deaths } \\
\text { Lags with significant } \\
\text { correlation, and } \\
\text { greatest correlation } \\
\text { at boldfaced lag }\end{array}$ & $\begin{array}{l}\text { Year-on-year } \\
\text { largest } \\
\text { decrease (2003 } \\
\text { vs. 2002) }\end{array}$ & $\begin{array}{l}\text { Year-on-year } \\
\text { largest increase } \\
(2003 \text { vs. 2002) }\end{array}$ & $\begin{array}{l}\text { Year-on-year } \\
\text { total change } \\
(2003 \text { vs. } \\
2002)\end{array}$ \\
\hline Bus passengers & $\begin{array}{l}\text { Lag }-1,-2 \\
-0.860\end{array}$ & $\begin{array}{l}\text { Lag } 0,-1,-2 \\
-0.856\end{array}$ & May: $-70.3 \%$ & March: $+7.7 \%$ & $-13.5 \%$ \\
\hline Subway passengers & $\begin{array}{l}\text { Lag } 0,-1,-2 \\
-0.850\end{array}$ & $\begin{array}{l}\text { Lag } 0,-1,-2 \\
-0.801\end{array}$ & May: $-62.4 \%$ & Sept: $+18.9 \%$ & $-2.1 \%$ \\
\hline Arriving airline passengers (INT) & $\begin{array}{l}\text { Lag } 0,-1,-2 \\
-0.923\end{array}$ & $\begin{array}{l}\text { Lag } 0,-1,-2 \\
-0.891\end{array}$ & May: $-98.2 \%$ & Jan: $+12.7 \%$ & $-25.0 \%$ \\
\hline Departing airline passengers (INT) & $\begin{array}{l}\text { Lag } 0,-1,-2 \\
-0.895\end{array}$ & $\begin{array}{l}\text { Lag } 0,-1,-2 \\
-0.892\end{array}$ & May: $-96.3 \%$ & March: $+8.0 \%$ & $-24.3 \%$ \\
\hline Arriving airline passengers (DOM) & $\begin{array}{l}\text { Lag }-2 \\
-0.515\end{array}$ & NS & June: $-56.6 \%$ & May: + 29.5\% & $-0.75 \%$ \\
\hline Departing airline passengers (DOM) & $\begin{array}{l}\text { Lag }-2 \\
-0.521\end{array}$ & $\begin{array}{l}\text { Lag }-2 \\
-0.437\end{array}$ & June: $-57.8 \%$ & May: $+39.5 \%$ & $+0.36 \%$ \\
\hline Hotel occupancy & $\begin{array}{l}\text { Lag } 0,-1,-2 \\
-0.867\end{array}$ & $\begin{array}{l}\text { Lag } 0,-1,-2 \\
-0.858\end{array}$ & May: $-81.5 \%$ & Jan: $+10.0 \%$ & $-18.1 \%$ \\
\hline International tourists & $\begin{array}{l}\text { Lag } 0,-1,-2 \\
-0.698\end{array}$ & $\begin{array}{l}\text { Lag } 0,-1,-2 \\
-0.715\end{array}$ & May: $-93.8 \%$ & Jan: $+12.4 \%$ & $-40.4 \%$ \\
\hline $\begin{array}{l}\text { Visitors from Hong Kong, } \\
\text { Macao and Taiwan }\end{array}$ & $\begin{array}{l}\text { Lag } 0,-1,-2 \\
-0.851\end{array}$ & $\begin{array}{l}\text { Lag } 0,-1,-2 \\
-0.842\end{array}$ & May: $-92.5 \%$ & Nov: $+24.1 \%$ & $-24.1 \%$ \\
\hline Air cargo & $\begin{array}{l}\text { Lag }-1,-2 \\
-0.561\end{array}$ & $\begin{array}{l}\text { Lag }-1 \\
-0.552\end{array}$ & May: $-51.2 \%$ & Oct: $+27.1 \%$ & $-1.1 \%$ \\
\hline Road cargo & NS & NS & May: $-22.4 \%$ & July: $+43.3 \%$ & $+7.2 \%$ \\
\hline Food expenditures & $\begin{array}{l}\text { Lag } 0,-1 \\
-0.625\end{array}$ & $\begin{array}{l}\operatorname{Lag} 3,0,-1,-5 \\
-0.586\end{array}$ & May: $-18.5 \%$ & Sept: $+14.4 \%$ & $+5.9 \%$ \\
\hline Cloth expenditures & $\begin{array}{l}\text { Lag } 3,0,-1,-6,-7 \\
-0.525\end{array}$ & $\begin{array}{l}\text { Lag } 0,-1,-6 \\
-0.551\end{array}$ & May: $-32.5 \%$ & Nov: $+24.2 \%$ & $+10.1 \%$ \\
\hline Expenditures on necessities & NS & NS & May: $-7.8 \%$ & Jan: $+24.9 \%$ & $+11.4 \%$ \\
\hline Retail account & $\begin{array}{l}\operatorname{Lag}-6 \\
+0.474\end{array}$ & $\begin{array}{l}\text { Lag }-6 \\
+0.479\end{array}$ & May: $-3.3 \%$ & Jan: $+31.2 \%$ & $+17.9 \%$ \\
\hline Food \& beverage services account & $\begin{array}{l}\text { Lag } 0,-1 \\
-0.717\end{array}$ & $\begin{array}{l}\text { Lag } 0,-1 \\
-0.649\end{array}$ & May: $-39.7 \%$ & Feb: $+43.5 \%$ & $+8.0 \%$ \\
\hline Wholesale account & NS & NS & No decrease & Feb: $+138.8 \%$ & $+92.2 \%$ \\
\hline Large retail account & $\begin{array}{l}\text { Lag }+6 \\
+0.484\end{array}$ & $\begin{array}{l}\text { Lag }+6 \\
+0.480\end{array}$ & May: $-8.2 \%$ & Jan: $+24.9 \%$ & $+6.6 \%$ \\
\hline
\end{tabular}

INT, international; DOM, domestic; NS, non-significant: no lag could be identified where cross-correlation is significant at a confidence level of twice the standard error.

*Assuming that the time series are not cross-correlated and that one of the series is white noise. 
At various lags in food and cloth expenditures, (barely) significant correlations were found, but this seems to be more coincidental than having any causal link with SARS (Table 1). The account for retail shows a weak positive tendency for lagging the SARS time series by 6 months, whereas the account for large retail shows a similar tendency for preceding it by 6 months. Although for all retail, this could be indicative of a weak tendency to postpone consumption in each month, and to make up for it later, it would not explain the tendency for large retail, and seems therefore also unrelated.

Furthermore, as could be expected, for wholesale, necessities and road cargo no significant correlation was found at any lag. Figure 3 illustrates this further by showing that expenditures in disposable income seem virtually unaffected by the SARS outbreak, other than that the average resident in Beijing [disposing on average of 1157 Chinese Yuan (or \$US 139) per month in 2003)] saved relatively more in the month of May. This seems to have been made up for in later months (especially after August), mostly by spending more on education and amusement (Figure 3). Note that in September 2002, Beijing residents on average spent more than they saved, and that both income and expenditure peak around the Chinese New Year period (in both 2002 and 2003, New Year's day was in February). Table 1 indicates that there does not seem to be a marked difference in correlations between any indicator and cases or deaths. For both case and death series individually, the delayed correlations are the most significant, even if they too should be slightly delayed with one another. However, cross correlation between the case and the death series is greatest at lag 0 (coefficient 0.937), implying an immediate direct impact between both time series when using a monthly time scale.

\section{Conclusion}

The impact of an infectious disease outbreak is uncertain, more so when that outbreak is of a new disease

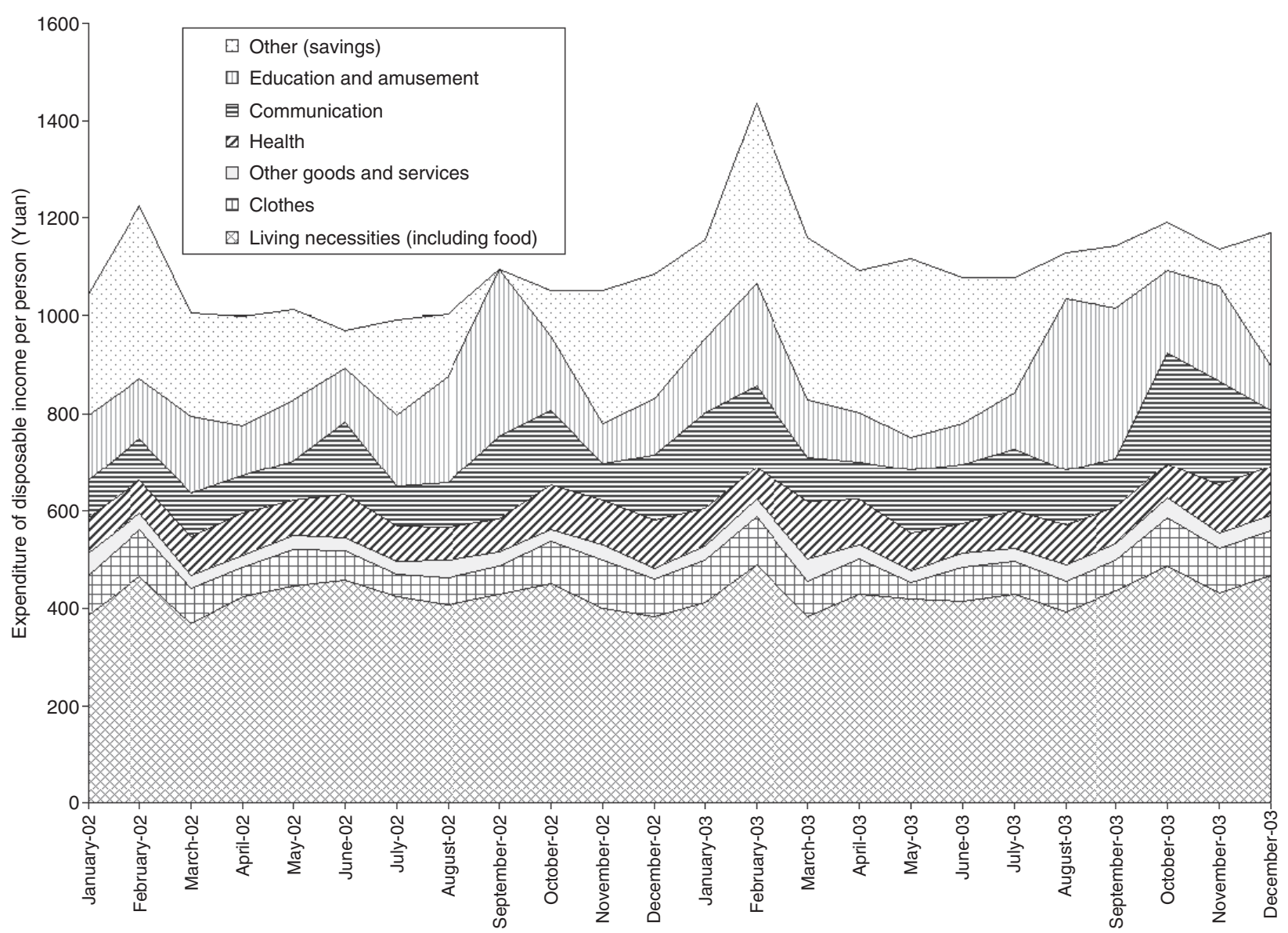

Figure 3 Monthly average disposable income and associated consumption patterns per Beijing resident (2002-2003). 
with unquantified mode and rate of transmission, infectivity and lethality (Smith et al. 2006). Outbreaks like SARS are predicted to generate immediate direct economic effects from the impact of the disease itself (health sector costs related to treatment of those infected), from policies to contain disease (public sector and private costs related to quarantine, isolation and school closure for instance) and from the fear that is generated by the outbreak, which will affect individual behaviour (Smith 2006).

These latter effects are arguably the most significant as they potentially range widely across the economy. As reported elsewhere (Sadique et al. 2007), there are predicted to be effects primarily related to social distancing; covering reduced travel, leisure pursuits, commercial activity and even employment rates. This would be expected to affect sectors comprising clothes, furnishings, cars, leisure, transport and tourism, for the duration of the outbreak. However, in some instances lost economic activity during the outbreak would be predicted to be regained once the outbreak is over, which has been termed the 'bounceback' effect (M. R. Keogh-Brown, personal communication). For instance, workers may work overtime to make up absence from work, consumers may undertake postponed purchases of consumer clothes or furnishings. In some cases though, the losses will be permanent, such as reductions in restaurant receipts or public transport. More indirect effects may include a reduction in foreign investment, which may be a result of the perception of how the outbreak was handled by an economy, and longer-term effects may be felt through traditional economic avenues according to the severity of the impact. It is these wider (non-health sector related) effects, related to reductions in consumption and investment patterns for instance, that make the usual form of economic quantification of the cost-of-illness inadequate in the case of an infectious disease outbreak, as discussed elsewhere (Beutels et al. 2008). Although there has been some empirical corroboration of these hypothesized effects (Keogh-Brown \& Smith 2008), additional evidence such as that presented in this paper is important to add validity to these causal pathways as they are used to specify the impact of shocks in macro-economic models of infectious disease outbreaks.

The overall macroeconomic impact of SARS in China was noticeable only as a slowing down of growth in the third quarter, and this impact dissipated over the year. However, in particular sectors there was a substantial decrease in consumption. Especially leisure activities (such as bars and restaurants), local and international transport, and tourism were impacted in the third quarter, but quickly rebounded in the fourth quarter after the crisis subsided. This is illustrated in depth in this paper for Beijing. SARS had a major impact on tourism (and travel in general), and all indirect consumption arising from it, as well as on local entertainment and transport in Beijing. We have shown that the delay to the first impact of SARS on related indicators is likely to be short ( 1 day to 1 month), but that more impacts are felt with longer delays thereafter.

An important limitation of this study is that we were only able to use data over a 2-year period. But 2002 and 2003 were the two most relevant years for the inferences we tried to make here for three main reasons. First, by the last quarter of 2003 we did not find any significant negative impact vs. 2002. Second, SARS caused a relatively small number of deaths before it was eradicated, and thus the permanent loss to the workforce it caused is negligible in view of the size of the Chinese workforce. Third, overall economic growth was $10 \%$ to $11 \%$ in each of the 4 years after the SARS crisis, so that any long lasting negative effect or bounceback of SARS would have been at least partly absorbed and therefore very difficult - if not impossible - to identify with significant statistical confidence.

Estimating the cost of the SARS crisis in Beijing is not straightforward. While we can establish reductions in consumption, much of this consumption is postponed and cannot be considered a permanent loss to the economy. With regard to irrecoverable consumption, we can speculate that the decline in tourism and consumption for leisure was at least partly irrecoverable. The year-on-year impacts per month serve then only as an indicator with the likely impact (assuming continued growth) being larger. For instance, assuming tourism would have continued to grow as in 2002, the 2003 reduction in foreign and domestic visitors in Beijing can be estimated at 1470000 and 60 000, respectively. Based on data from the year 2000 (Hsyndicate 2008), using an average length of stay of 4 days, and a daily expenditure of US\$230 for foreigners and US\$ 220 for domestic visitors, this translates into a loss of US\$ $1.4 \mathrm{bn}$. Clearly, this estimate is speculative and arguably conservative, yet considerable enough to indicate that SARS had a large monetary impact in Beijing, even when narrowing the impact down to the tourist sector. It was previously estimated that the health care cost per SARS patient in Beijing was 17150 Chinese Yuan (or about US\$ 1886) (Xiao et al. 2004). This would amount for 2521 cases in Beijing to total treatment costs of US\$ $4.8 \mathrm{~m}$. This simple calculation tells us that the losses to the tourist sector alone were about 300 -fold that of the cost of treatment for SARS cases in Beijing. 
P. Beutels et al. Economic impact SARS

\section{Acknowledgements}

This study was supported by the Commission of the European Community under the Sixth Framework Program Specific Targeted Research Project, SARS Control 'Effective and Acceptable Strategies for the Control of SARS and new emerging infections in China and Europe' (Contract No. SP22-CT-2004-003824).

\section{Conflicts of interest}

The authors have declared no conflicts of interest.

\section{References}

Beutels P, Edmunds WJ \& Smith RD (2008) Partially wrong? Partial equilibrium and the economic analysis of public health emergencies of international concern. Health Economics 17, 1317-1322.

Donnelly CA, Fisher MC, Fraser C et al. (2004) Epidemiological and genetic analysis of severe acute respiratory syndrome. Lancet Infectious Diseases 4, 672-683.

Hamori S (2003) An Empirical Investigation of Stock Markets. The CCF Approach. Research Monographs in Japan-U.S. Business and Economics. 8, 17-9. Kluwer Academic Publishers, Dordrecht, The Netherlands/MA, USA.
Hsyndicate (2008) Beijing Hotel Market Overview. Available at: http://www.hsyndicate.org/news//4010225.html (accessed on 7 February 2008).

Keogh-Brown MR \& Smith RD (2008) The economic impact of SARS: how does the reality match the predictions? Health Policy 88, 110-120.

Ministry of Public Health (2003) The statistical bulletin of SARS. $\mathrm{MoH}$, Beijing.

Norpoth H (1984) Economics, politics, and the cycle of presidential popularity. Political behaviour 6, 253-273.

Sadique MZ, Edmunds WJ, Smith RD et al. (2007) Precautionary behavior in response to perceived threat of pandemic influenza. Emerging Infectious Diseases 13, 1307-1313.

Smith RD (2006) Responding to global infectious disease outbreaks: lessons from SARS on the role of risk perception, communication and management. Social Science \& Medicine 63, 3113-3123.

Smith RD, Drager N \& Hardimann M (2006) The Rapid Assessment of the Economic Impact of Public Health Emergencies of International Concern. Oxford University Press, Oxford.

WHO (2008) Severe Acute Respiratory Syndrome (SARS). Available at: http://www.who.int/csr/sars/country/en/index.html (accessed on 7 February 2008).

Xiao F, Chen BW, Wu YF et al. (2004) Analysis on the cost and its related factors of clinically confirmed severe acute respiratory syndrome cases in Beijing. Zhonghua Liu Xing Bing Xue Za Zhi $25,312-316$.

Corresponding Author Wu-Chun Cao, Beijing Institute of Microbiology and Epidemiology, State Key Laboratory of Pathogen and Biosecurity, 20 Dong-Da Street, Feng Tai District, 100071 Beijing, China. E-mail: caowc@nic.bmi.ac.cn 